\title{
More changes in NASA's higher echelons
}

\section{Washington}

BEFORE the resumption of the public inquiry by the President's commission at the beginning of this week, the US National Aeronautics and Space Administration (NASA) had begun clearing the ground for a reorganization at the top. The post of head of the shuttle programme has been filled by the appointment of RearAdmiral Richard $\mathrm{H}$. Truly, a former astronaut. His predecessor, Jesse Moore, who had been appointed at the end of last year as director of the Johnson Space Center at Houston, has taken up that post sooner than planned.

Meanwhile, the administrator of NASA, James C. Beggs, remains on indefinite voluntary suspension, after his indictment at the end of last year on criminal charges levelled by the Department of Defense against General Dynamics, the military contractor of which Mr Beggs had previously been a vice-president. NASA is for the time being the responsibility of William Graham, previously Beggs' deputy, but the appointment of a permanent adminstrator is expected shortly.

The commission's preliminary inquiries have taken its members separately to sites such as Cape Canaveral and the Morton Thiokol plant in Utah at which the suspect solid-fuel boosters for the shuttle were manufactured.

In the process, Dr Richard Feynman, the Nobel physicist from the California Institute of Technology, seems on the way to becoming as well known to the general public as he is famous within the academic community. He spent much of last week at Cape Canaveral looking into reports that parts of the lost shuttle craft, and in particular the lower part of the booster that appears to have failed, became exceptionally cold in the hours before the launch. Several theories of the processes that might account for this have been developed.

Documents released by NASA support the speculation (see Nature 319, 609; 1986) that the fault responsible for the disaster on 28 January was the failure of one of the synthetic rubber-based sealing rings joining the lowest of the four sections of the right-hand booster rocket to that above.

At an earlier stage, there had been concern about the putty used for filling the joins. According to one of the documents, the original material (based on zinc chromate) had contained asbestos, but this was withdrawn from the market under Environmental Protection Agency regula- tions. More recently, putty containing asbestos was obtained from a Canadian source, but is described as having been more "tacky" and thus less suitable. By August last year, Thiokol had submitted no fewer than 43 alternative designs for

\section{Solar telescope}

\section{US and China join with Europe}

LEST, the Large European Solar Telescope project, scheduled to become operational at the beginning of the $1990 \mathrm{~s}$, has changed its name. At the fourth general assembly of the LEST foundation in Teneriffe (29 January-3 February 1986), two new countries, China and the United States, formally joined LEST, and the "E" of the acronym was accordingly changed to mean "Earth-based". The participation of these two countries (and also of Australia) will undoubtedly affect the choice of a site for the telescope. The original plan was for a site in the Canary Islands, but, with the United States interest in the project, the idea of Hawaii has, in the words of one participant in the general assembly, "gradually crept in". Solar photographs from the new Swedish telescope at La Palma convinced many of the participants that an Earth-based facility makes scientific sense.

One main purpose of LEST will be to study solar magnetic fields (by means of polarized light observations), and, in particular, their evolution with time. This will require not only a good telescope (the designs for LEST show a 2.4-m aperture; the largest solar telescope at present is the 1.5-m instrument at Kitt Peak, Arizona), but also a site with good optical quality for a significant proportion of the time. Although La Palma can occasionally have very bad weather in winter this is of relatively short duration, and the photographs obtained by the Swedes since their telescope went into operation on $13 \mathrm{De}$ cember greatly impressed the participants in the LEST assembly. Dr Hou Ningsheng, of the Yunnan Observatory in Chi-

\section{CERN inquiry}

AN international review of the European Organization for Nuclear Research (CERN) is to be set up following a unanimous decision by its council last week. The result of a British initiative (see Nature 319, $525 ; 1986)$, the review is expected to be completed within twelve months. the case-to-case sealing joints, one of which has been incorporated into a new design of rocket case. Estimates of the time needed to modify existing cases range from 3 to 12 months.

Fears that similar design problems may affect the solid-fuelled ICBM rockets of the US Strategic Air Command are apparently inapplicable. A spokesman at Omaha, Nebraska, said last week that both the Minuteman and the MX (Peacekeeper) rockets consist of three stages each of which is integral in construction. na, was particularly enthusiastic about the Swedish results, which clearly show that time-development studies are feasible from a ground-based instrument.

Sweden has a special interest in LEST. The Royal Swedish Academy of Sciences has acted as "host" to the LEST organization since it was established in 1983, and has provided seed-money for feasibility studies. Dr Kai-Inge Hillerud of the Swedish academy is the executive secretary of the organization. The project manager and newly appointed director of the project is a Norwegian, Dr Oddbjorn Engvold of the Theoretical Astrophysics Institute in Oslo.

Apart from the choice of site (for which testing is about to begin in the Canaries and Hawaii), the two main problems are finance and technology. There are now nine nations in LEST (Sweden, Norway, West Germany, Switzerland, Italy, Israel, Australia, China and the United States), each represented through a nongovernmental organization. How the cost of the project (estimated at US\$20 million) will be shared has not yet been decided. One proposal is for minimum contributions based on the ratios of members' Gross National Products, possibly with additional support from foundations and individual benefactors. Some private finance has, indeed, already been forthcoming - the technical design study for the proposed telescope was financed by Robert Maxwell, the British publishing magnate.

The "next generation" technology envisaged by this study will include active and adaptive optical systems to correct for atmospheric distortion and a sophisticated data storage and computer base. An important feature of LEST will be that observations can be carried out either by on-site staff or from remote-control observation rooms in the host countries. Although Earth-based, LEST will, in effect, be run, in Dr Engvold's words, as a "space instrument" and the technological problems it will pose are likely to prove extremely challenging.
Vera Rich 